children with impaired splenic function: a study of compliance. Pediatrics 1982;70:926-30.

8 Black J, Laws S. Living with sickle cell disease. London: Sickle Cell Society, East London Branch, 1986

9 Letter from Chief Medical, Nursing and Dental Officers. Haemoglobinopathy cards. London: Department of Health and Social Security. 1988. (PL/CMO (88) 11 )

10 John AB, Ramlal A, Jackson H, Maude GH, Sharma AW, Serjeant GR. Prevention of pneumococcal infection in children with homozygous sickle cell disease. BrMed f 1984;288:1567-70.

11 Buchanan GR, Smith SJ, Holtkamp CA, Fuseler JP. Bacterial infection and splenic reticuloendothelial function in children with hemoglobin SC disease. Pediatrics 1983;72:93-8.

12 Buchanan GR, Smith SJ. Pneumococcal septicemia despite pneumococcal vaccine and prescription of penicillin prophylaxis in children with sickle cell anemia. Am $\mathcal{J}$ Dis Child 1986;140:428-32.

13 Griffiths PD, Mann JR, Darbyshire PJ, Green A. Evaluation of eight and a half years of neonatal screening for haemoglobinopathies in Birmingham. BrMed f 1988:296:1583-5.
14 Horn MEC, Dick MC, Frost B, et al. Neonatal screening for sickle cell diseases in Camberwell: results and recommendations of a two year pilot study. BrMed f 1986;292:737-40.

15 Rowley PT. Newborn screening for sickle cell disease. Benefits and burdens. N Y State F Med 1978;78:42-4

16 Grover R, Wethers D, Shadidi S, Grossi M, Goldberg D, Davidow B. Evaluation of the expanded newborn screening program in New York City. Pediatrics 1978:61:740-9.

17 O'Brien RT, McIntosh S, Gregg TA, Pearson HA. Prospective study of sickle cell anemia in infancy. F Pediatr 1976;89:205-10.

18 Brozovic M, Anionwu E. Sickle cell disease in Britain. I Clin-Patho 1984;37:1321-6.

19 Cochrane AL, Holland WW. Validation of screening procedures. Br Med Bull $1971 ; 27: 1-8$.

20 Franklin IM. Services for sickle cell disease: unified approach needed. Br Med $\mathcal{f}$ 1988;296:592.

(Accepted 11 October 1989)

\title{
Open access gastroscopy: Too much to swallow?
}

\author{
D D Kerrigan, S R Brown, G H Hutchinson
}

\begin{abstract}
Objectives-To ascertain the proportion of endoscopic examinations with normal findings in patients referred for gastroscopy through hospital medical staff or directly by their general practitioner and to assess the likely effect of targeting endoscopy in older patients.
\end{abstract}

Design-Retrospective audit of the gastroscopy practice of one consultant from 1986 to 1988 from information recorded on a standard form completed at the time of the examination, which contained details of patients, their endoscopic findings, and mode of referral (open access or clinic).

Setting-One district general hospital.

Patients - 1545 Consecutive patients from primary catchment area attending for their first gastroscopy; 454 were referred through the outpatient clinic or by hospital colleagues (clinic group) and 1091 were accepted for endoscopy solely on their general practitioner's clinical diagnosis (open access group).

Results-Similar numbers (about $40 \%$ ) of examinations with normal findings were performed in each group, although in patients aged over 40 the proportion with normal findings was significantly higher in the clinic group $(p<0 \cdot 03)$. Endoscopic evidence of gastro-oesophageal reflux disease, peptic ulceration, and gastroduodenal inflammation was equally common in each group; upper gastrointestinal malignancy, however, was significantly more common in patients referred through hospital doctors $(5 \%, 23 / 454 v 2 \%, 22 / 1091$ respectively; $\mathbf{p}<\mathbf{0 . 0 0 5}$ ) (although many of these patients had already been extensively investigated).

Implications - Open access gastroscopy does not increase the number of unnecessary examinations and should become more widely available. Targeting this service to patients aged over $\mathbf{4 0}$ would reduce the number of requests but increase the diagnostic yield.

\section{Introduction}

Providing general practitioners with free or open access to upper gastrointestinal endoscopy services offers patients the opportunity of rapid diagnosis and treatment. It also reduces the burden on hospital outpatient departments' and minimises diagnostic endoscopy in patients who have already been treated by the time the examination is eventually performed. Many endoscopy units, however, are reticent about permitting such access, fearing a massive increase in workload and an unacceptable increase in the number of "unnecessary" examinations, which disclose normal findings. It has been proposed that the application of diagnostic scoring systems ${ }^{23}$ by general practitioners might lead to more selective open access referral patterns, but such systems are commonly cumbersome and even simple systems may fail to gain wide acceptance in a busy surgery. The aim of this study was to elucidate whether unselected open access gastroscopy generates excessive numbers of examinations with normal findings. In addition, as it has been claimed that the investigation of dyspepsia in younger patients rarely influences management ${ }^{4}$ we have stratified our data by age and assessed the effect on endoscopic yield of targeting endoscopy resources in older groups of patients.

\section{Subjects and methods}

An open access gastroscopy service has been available at Halton District General Hospital since 1986. Local general practitioners were informed of the service by letter and were sent regular reminders several times each year. In a retrospective audit of a single consultant's (GHH) gastroscopy practice we compared the endoscopic findings in 1091 unselected patients (581 males, 510 females) accepted for their first gastroscopy solely on the clinical diagnosis of their general practitioner with those in 454 patients (193 males, 261 females) referred internally (through the outpatient clinic or by other hospital colleagues). The age distribution of the two groups was similar (median age (range) 48 (13-91) years and 51 (14-92) years respectively).

A $\chi^{2}$ test was used to compare differences in the prevalence of upper gastrointestinal disease and in the proportion of abnormal and normal findings on gastroscopy in each group. In examinations in which bile reflux was present in a stomach with normal mucosa the findings were reported as normal; analysis of our data taking simple bile reflux as an abnormal finding did not alter our conclusions.

\section{Results}

Table I summarises the endoscopic findings. Accepting unselected patients for upper gastrointestinal endoscopy did not result in an increase in the proportion of examinations that disclosed normal findings. Furthermore, the proportions of patients with gastro-oesophageal reflux disease (hiatus hernia, oesophagitis, benign ulceration, and stricture) and 
peptic ulceration were also remarkably similar in open access and clinic referrals. Interestingly, although gastroduodenal inflammation was present in about $15 \%$ of endoscopies in each of the two groups, gastritis was more common in clinic patients $(12.5 \%(57 / 454) v$ $7 \cdot 5 \%(82 / 1091) ; \mathrm{p}=0.001)$ whereas duodenitis was seen more commonly in open access referrals $(8 \%(87)$ 1091) $v 2 \%(9 / 454) ; \mathrm{p}<0 \cdot 001)$. Malignant disease was detected in a higher proportion of the patients referred from within the hospital (5\% (23/454) v 2\% (22/1091); $\mathrm{p}<0.005)$.

Table II shows how the pattern of referral for gastroscopy varied between general practitioners and hospital clinicians, according to the patients' age. About $80 \%$ (368/454) of patients referred from within the hospital were aged over 40 ; in contrast, general practitioners tended to refer patients over a broader age range, referring almost twice as many younger patients $($ aged $<40)$ as their hospital counterparts. However, when the number of examinations with normal findings (expressed as the ratio of abnormal to normal findings) was compared in patients of different ages (figure) preselection of younger patients for endoscopy by a hospital clinician did not result in increased numbers of positive endoscopic diagnoses. Furthermore, in the patients aged over 40 general practitioners were significantly better at selecting those likely to have abnormal findings at endoscopy $(p<0.03)$, particularly in the elderly (aged over $70 ; p=0.05$ )

\section{Discussion}

The demand for gastroscopy continues to grow, provoking calls for endoscopy services to be targeted at selected groups of patients. ${ }^{23}$ In practice, however, most patients are selected for endoscopy according to the clinical judgment of a doctor in the outpatient clinic. Clearly, a system that permitted general practitioners unrestricted access to hospital gastroscopy services might have the advantage of permitting more rapid diagnosis and treatment. An additional benefit (both for the NHS and the patient) is the elimination of at least one unnecessary outpatient attendance. Perhaps understandably, many gastroenterologists view the proposal to delegate control of access to general practitioners as an invitation for their service to be paralysed by large numbers of inappropriate referrals. Our results, however, provide strong evidence in favour of adopting an open access policy as the overall proportion of examinations with normal findings was

TABLL: I-Endoscopic diagnoses in open access and clinic groups. Figures are numbers (percentages) of patients

\begin{tabular}{lccc}
\hline & $\begin{array}{c}\text { Open access } \\
n=1091\end{array}$ & $\begin{array}{c}\text { Clinic } \\
(\mathrm{n}=454)\end{array}$ & p Valuc \\
\hline $\begin{array}{l}\text { Normal } \\
\text { Gastro-oesophageal reflux and }\end{array}$ & $436(40)$ & $177(39)$ & $\mathrm{NS}$ \\
$\quad$ associated discase* & $251(23)$ & $109(24)$ & $\mathrm{NS}$ \\
$\begin{array}{l}\text { Gastroduodenal inflammation } \\
\text { Peptic ulceration }\end{array}$ & $164(15)$ & $68(15)$ & $\mathrm{NS}$ \\
Malignancy & $207(19)$ & $73(16)$ & $\mathrm{NS}$ \\
Othert & $22(2)$ & $23(5)$ & $<0 \cdot 005$ \\
& $11(1)$ & $4(1)$ & NS
\end{tabular}

*Hiatus hernia, oesophagitis, oesophageal ulceration, stricture, and Barrett's oesophagus.

tForeign body, Mallorv-Weiss tear, and oesophageal varices.

TABLE II - Age distribution in open access and clinic groups. Figures are numbers (percentages) of patients

\begin{tabular}{lcc}
\hline Age group & $\begin{array}{c}\text { Open access } \\
(\mathbf{n}=1091)\end{array}$ & $\begin{array}{c}\text { Clinic } \\
(\mathbf{n}=454)\end{array}$ \\
\hline $0-30$ & $187(17)$ & $40(9)$ \\
$31-40$ & $229(21)$ & $46(10)$ \\
$41-50$ & $188(17)$ & $59(13)$ \\
$51-60$ & $197(18)$ & $70(15)$ \\
$61-70$ & $157(14)$ & $99(22)$ \\
$>70$ & $133(12)$ & $140(31)$ \\
\hline
\end{tabular}

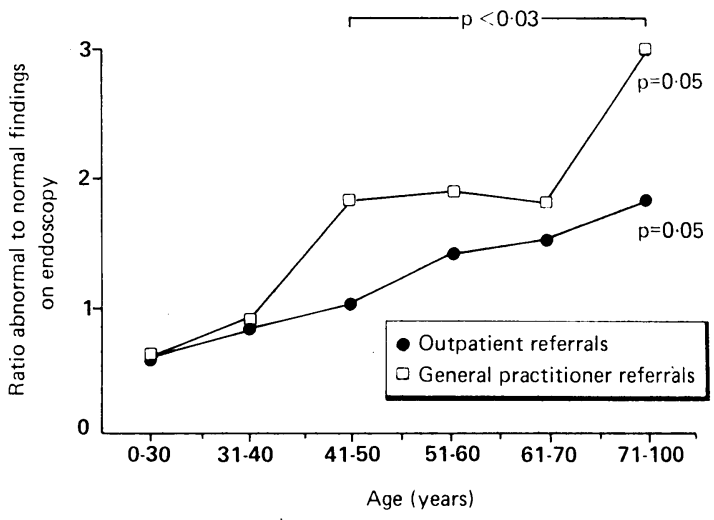

Comparison of ratio of abnormal to normal findings on endoscopy in open access and clinic patients of different ages

identical in open access and clinic referrals. Furthermore, in patients aged over 40 (in whom most disease would be expected) our findings indicate significantly more efficient use of endoscopy services by general practitioners than their hospital colleagues, perhaps reflecting their skill in recognising normality, in contrast to hospital doctors, whose training is mainly directed towards detecting abnormality.

A rate of negative gastroscopy of $40 \%$ may be considered to be too high by many endoscopists, but this figure is similar to that reported in earlier studies ${ }^{136}$ and was not reduced by requiring patients to attend a preliminary interview in the hospital clinic. In addition, the value of a normal gastroscopy result or one in which fairly minor disease is found should not be underestimated. Not only do such examinations remove serious upper gastrointestinal disease from clinicians' differential diagnosis but they also provide strong reassurance for doctors and patients and should lead to less empirical treatment and reduced prescribing costs. Although most upper gastrointestinal diagnoses were equally common in both groups of patients, our results showed an increased prevalence of malignant disease in patients referred from within the hospital $(5 \% v 2 \%)$. This may represent a genuine difference in referral practice: general practitioners who suspect cancer may prefer their patients to be assessed by a hospital specialist, reassured that an urgent referral should ensure an early appointment. However, as many patients with upper gastrointestinal malignancy were secondary referrals from within the hospital some had already had preliminary investigations, and they may thus represent a preselected group of subjects.

The number of requests generated by the open access service at this hospital has gradually increased since its instigation in 1986, from about 17 examinations/week in the first 12 months of the scheme to $24 /$ week in the second 12 months, although this additional workload has been absorbed without expanding the number of available endoscopy sessions. Furthermore, our most recent figures for 1989 indicate that growth in the demand for endoscopy begins to plateau after a while (about 29 examinations/week from January to June 1989 inclusive), a finding which has been confirmed in another, larger study. ${ }^{\circ}$ Clearly, if an endoscopy unit is already working at almost full capacity even the fairly limited increase in workload associated with introducing open access gastroscopy might prove difficult to manage. Restriction of open access gastroscopy to patients aged over 40 , however, might reduce the number of requests by almost $40 \%$ and yet lead to an increase in the diagnostic yield obtained (table II, figure).

Providing general practitioners with open access to gastroscopy services permits more rapid diagnosis and treatment and reduces unnecessary outpatient attendance. Our results indicate that scepticism about 
the potential value of an open access service is unfounded, and we believe that this service should become more widely available.

1 Fisher JA, Surridge JG, Vartan CP, Lochry CA. Upper gastrointestinal endoscopy-a GP' service. Br. Med Y 1977;ii:1199-201.

2 Mann J, Holdstock (G, Harman M, Machin D), Lochry CA. Scoring sistem to improve cost effectiveness of open access endoscopy. Br. Med J 1983;287 $937-40$
3 Holdstock G, Harman M, Machin D, Parel C, Llowd RS, Prospective testing of a coring system designed to improve case selection for upper gastrointestinal

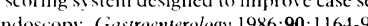

+ Mead GM, Harris A, Webster (iK, Langman MJS. Uses of barium meal examination in despeptic patients under 50 years. Br.Med 7 1977;ii: 1460-1.

Mathers N. Hodgkin P. The Gatekeeper and the Wizard: a fairy tale. Br Med $1989 ; 298: 172-4$

6 Gear MWL, Wilkinson SP. Open-access upper alimentary endoscopy. Br $\mathrm{f}$ Hosp Med 1989;41:438-4t

\title{
Cervical cytology in the Vale of Trent faculty of the Royal College of General Practitioners, 1985-8
}

\author{
Andrew Wilson
}

\begin{abstract}
Objective-To assess changes in the organisation and performance of cervical cytology programmes in the practices of members of the Vale of Trent faculty of the Royal College of General Practitioners.

Design-Retrospective audits completed in 1985 and 1988 by general practitioners on a sequential sample of 100 records of women aged 35-64 in their practice.
\end{abstract}

Setting-General practices in which one or more partners were members or associates of the Vale of Trent faculty of the college, of which 76 participated in the first audit and 55 (82\% of 67 eligible practices) in the second.

Subjects-Sequential samples of 100 women born between 1 January 1920 and 31 December 1949 (first audit) and between 1 January 1923 and 31 December 1952 (second audit) whose surnames began with $P$ or $B$ respectively.

Main outcome measures-Percentage of women in each practice with a record of cervical cytology performed in the previous five years and percentage with no recorded smear.

Results - Of the 76 practices completing the audit in $1985,55(82 \%$ of those eligible) repeated the exercise in 1988. Performance was not significantly different in practices that did and did not respond. The median percentage of women who had had a smear in the previous five years was $49 \%$ and $69 \%$ in 1985 and 1988 respectively $(p<0.001)$ and that of women with no record of a cervical smear was $28 \%$ and $16 \%$ respectively $(p<0 \cdot 001)$. All but six practices showed improvement in both outcome measures. In both audits an active call system was associated with a significantly increased performance $(p<0 \cdot 05)$. In nine practices $(16 \%) 80 \%$ or more of the samples of women had had a smear in the previous five years.

Conclusion-Organisation and performance of practices audited improved between 1985 and 1988 . Although this might result from participation in the first audit, it probably represents a more general trend within primary care.

Action-Between the two audits more practices $(87 \% v 67 \%)$ had developed a policy on screening, and this was more likely to include the aim of performing regular smears on all sexually active women $(98 \% v 80 \%)$.

Department of General Practice, University of Nottingham, Queen's Medical Centre,

Nottingham NG7 2UH Andrew Wilson, MRCGP, lecturer

$\operatorname{Br} \operatorname{Med} \mathcal{F} 1990 ; 300: 376-\varnothing$
2004 women in England and Wales in 1986, 1 most of which might have been prevented by achieving high rates of coverage in a coordinated cervical cytology programme.' Participation by general practitioners is an essential feature of any such programme, but a recent national survey showed that only $43 \%$ of general practitioners operated a screening system that could identify and call previously untested women. ${ }^{3}$ The rate of coverage of a programme is the crucial determinant of its success, ${ }^{+}$although these rates are difficult to determine as routinely published data on cytology are presented as numbers of smears rather than number of women. The government has recently proposed a target of $80 \%$ coverage for women who have had a smear within the previous five years, excluding those who have had a hysterectomy. ${ }^{\circ}$ Participation in peer group audit improves general practitioners performance, at least for those directly involved. "7 The Royal College of General Practitioners has proposed peer group audit as a major route to higher standards, and local faculties have been encouraged to stimulate such activity.

I describe one initiative in which members of the college were invited to audit the organisation and performance of their cervical cytology programmes. The audit was repeated three years later. The aim of these audits was to detect any features of the programmes associated with high performance and to report changes over the three years.

\section{Subjects and methods}

In spring of 1985 members of the Vale of Trent faculty of the Royal College of General Practitioners were invited to take part in an audit of cervical cytology." They were asked about their policy on cervical smears and requested to audit their performance by drawing a sequential sample of 100 women born between 1 January 1920 and 31 December 1949 from their records, starting with records filed under the letter P. Practices in which more than one doctor received the questionnaire were asked to submit only one audit. The audit was performed in 76 practices, representing 101 members $(42 \%$ response rate). The performance measures were the number of women in the sample who had no record of a smear and the number who had had a smear in the previous five years. Respondents were sent their own results, aggregate results of the audit, and their order of rank.

In spring 1988 a second audit was planned. Of the 76 doctors who had performed the first audit, 69 were thought still to be in post and were invited to repeat their audit, using an identical method, but this time selecting 100 women born between 1 January 1923 and 31 December 1952, starting from the letter B in their records. After the initial posting it was realised that one doctor had moved and another had retired, reducing the denominator to 67 practices. The results of the second audit were compared with those of the first with non-parametric tests. 